\title{
AKULTURASI DALAM ARSITEKTUR RUMAH TINGGAL LASEM Studi Kasus Rumah Liem King Siok
}

\author{
M. Maria Sudarwani' ${ }^{1}$ Edi Purwanto², Siti Rukhayah ${ }^{2}$ \\ 1 Fakultas Teknik, Universitas Pandanaran, \\ 2 Fakultas Teknik, Universitas Diponegoro, \\ Email:maria@unpand.ac.id
}

\begin{abstract}
The Acculturation in Architecture of Lasem House; A Case Study of Liem King Siok House

Lasem was called "La Petit Chinois" or "Small China" because there were Chinese community settlements consisting of old Chinese-style houses. Lasem was a large port city since the time of the Majapahit Kingdom until the Dutch colonialism encouraged cultural acculturation. Lasem batik is one of the results of acculturation of Javanese and Chinese culture and has been a noble outfit since King Lasem I ruled (1350-1375). Cultural acculturation forms a distinctive cultural identity that is an important part of coastal culture. Therefore the uniqueness of cultural acculturation in Lasem is interesting to study. The purpose of this study was to obtain an overview of Chinese residential architecture in Lasem Chinatown and Chinese culture in Lasem, so as to enrich local theories about the meaning behind the architecture of Chinese houses in Lasem. This research method uses the rationalistic paradigm with a qualitative approach. Cultural acculturation influences local architecture through variety, pattern of space, and order, so that the result of mixing culture will form a new image of local society (Fauzy, 2012). The culture acculturation has influenced the spatial layout and details of the residential houses of the Chinese community so as to produce a unique form of architecture.
\end{abstract}

Key words: cultural acculturation, architecture of Lasem houses

\section{Pendahuluan}

Wilayah Nusantara terletak pada persilangan jalan, antara Samudera Hindia dan Samudera Pasifik, atau lebih khusus, Benua Asia dan Australia. Persilangan ini telah menjadikan wilayah Nusantara sebagai tempat persinggahan bagi pelayar dan pedagang terutama dari China ke India atau sebaliknya. Persinggahan para pelayar dan pedagang dari berbagai mancanegara telah menjadikan Nusantara sebagai tempat kehadiran semua kebudayaan besar di dunia. Bukti-bukti penemuan artefak-artefak seperti prasasti, uang logam dan gerabah memberikan informasi kehadiran bangsa-bangsa besar tersebut (Fitri, 2006). Kehadiran bangsa- bangsa besar ke Indonesia menyebabkan terjadinya akulturasi budaya dan menunjukkan bahwa bangsa kita mudah bergaul dengan orang luar Negara Indonesia. Mengenai pengertian tentang akulturasi, Koentjaraningrat (1977) mengemukakan bahwa: akulturasi adalah proses sosial yang timbul bila suatu kelompok manusia dengan suatu kebudayaan tertentu dihadapkan dengan unsur-unsur dari suatu kebudayaan asing dengan sedemikian rupa, sehingga unsur-unsur kebudayaan asing tersebut lambat laun diterima dan diolah kedalam kebudayaan sendiri tanpa menyebabkan hilangnya kepribadian budaya itu sendiri. Perhatian terhadap saluran- 
saluran yang dilalui oleh unsur-unsur kebudayaan asing untuk masuk kedalam kebudayaan penerima, akan memberikan suatu gambaran yang konkret tentang jalannya suatu proses akulturasi. Menurut Afifah dkk (2007), dasar pijakan akulturasi adalah adanya unsur-unsur kebudayaan tertentu dihadapkan unsur-unsur kebudayaan asing, dua kebudayaan atau lebih yang saling mempengaruhi, budaya-budaya berbeda. Secara alami atau lambat laun diterima dan diolah dalam kebudayaan sendiri, penggabungan, pengkondisian seorang anak, diadaptasikan, pengaruh yang berulang-ulang dengan cara kontak langsung. Tanpa menghilangkan kepribadian kebudayaan itu, pola-pola atau kebiasaan-kebiasaan dari sebuah kebudayaan, sesuatu yang baru atau budaya yang berbeda yang kurang lebih merupakan pola-pola yang lebih kompleks atau lebih sempurna."Wujud" dan "isi" kebudayaan yang terjadi dalam proses akulturasi itu sekurang-kurangnya ada tiga macam, yaitu: a) Berupa sistem budaya (cultural system) yang terdiri dari gagasan, pikiran, konsep, nilai-nilai, norma, pandangan, dan sebagainya yang berbentuk abstrak, yang dimiliki oleh pemangku kebudayaan yang bersangkutan merupakan ide-ide (ideas). Cultural system ini kiranya tepat disalin dalam bahasa Indonesia dengan "tata budaya kelakuan;” b) Berbagai aktivitas (activities) para pelaku seperti tingkah laku berpola, upacara-upacara yang wujudnya konkret dan dapat diamati yang disebut social system atau sistem kemasyarakatan yang berwujud "kelakuan;" dan c) Berwujud benda (artefacts), yaitu benda-benda, baik hasil karya manusia maupun hasil tingkah lakunya yang berupa benda, yang disebut material culture atau "hasil karya kelakuan" (Soekiman, 2000: 40-41). Akulturasi budaya yang terjadi di Lasem merupakan representasi dan percampuran budaya pendatang dan budaya lokal yang terbentuk melalui perjalanan panjang sejarah budaya pesisir Jawa sejak abad ke- 14. Berdasarkan periodisasi dari waktu ke waktu dan adanya gelombang migrasi dari multi etnis ke Lasem terlihat konfigurasi budaya yang membentuk Lasem yaitu budaya Jawa, Cina, Arab dan Kolonial. Pengaruh Arab terjadi karena Lasem juga dijuluki Kota Santri dan tumbuh sebagai pusat jaringan penyebaran Islam. Hasil akulturasi budaya yang terlihat menonjol di Lasem yaitu bahasa, arsitektur, batik dan ritual (Nurhajarini dkk., 2015). Adapun akulturasi dalam arsitektur rumah tinggal China dikemukakan oleh Setiadi Sopandi dalam bukunya Sejarah Arsitektur Sebuah Pengantar (2013: 65), yaitu: arsitektur Rumah Cina di Lasem dianggap memiliki karakteristik yang merupakan hasil perpaduan antara arsitektur rumah Jawa dan arsitektur rumah Cina Selatan. Struktur bangunan Cina di Lasem kebanyakan menggunakan teknik dengan dua dinding penahan sebagai struktur utama yang menopang balok-balok lantai dan kudakuda. Selain itu, penerapan dinding batas rumah juga dianggap merupakan warisan kebudayaan Cina. Pengaruh penataan arsitektur Jawa diperlihatkan pada hubungan antara keberadaan elemen bangunan depan (pendhopo), bangunan samping dan belakang, dengan bagian rumah utama. Menurut LMF Purwanto (2017), Akulturasi budaya dalam arsitektur yang telah terjadi mempengaruhi tata ruang dan detail bangunan di Lasem yang dirancang dalam bentuk arsitektur yang unik. Permasalahannya banyak rumah tinggal Tionghoa di Pecinan Lasem yang mulai berubah, rusak dan hilang dikarenakan banyak factor. Rumah tinggal di Lasem terutama yang berarsitektur Tionghoa telah banyak ditinggalkan penghuninya. Anak mereka banyak yang belajar di kota Jakarta, Bandung, Surabaya dan Semarang yang selanjutnya bekerja di kota itu juga. Akibatnya penghuni Lasem yang kebanyakan orang tua meninggalkan dan membiarkan rumah mereka kosong karena mengikuti anaknya pindah ke kota lain, sehingga rumah tersebut menjadi rusak dan tidak terawat, maupun diubah fungsi menjadi garasi bus/truk atau menjadi 
gudang. Rumah tinggal Tionghoa di Pecinan Lasem mempunyai arsitektur khas yang relatif bertahan dan perlu dijaga keberadaannya, sehingga penting untuk menemukan keunikannya agar dapat ditentukan cara menjaganya. Berdasarkan uraian di atas, maka pertanyaan penelitian yang signifikan untuk diajukan menjadi pegangan dalam kegiatan penggalian data dan informasi dari para informan masyarakat penghuni rumah tinggal dan para tokoh masyarakat di Pecinan Lasem adalah sebagai berikut: Apa yang khas pada arsitektur rumah tinggal Tionghoa di Pecinan Lasem dan lingkungan permukimannya? Tujuan penelitian ini adalah mendapatkan gambaran arsitektur rumah tinggal Tionghoa di Pecinan Lasem sehingga dapat memperkaya teori lokal tentang arsitektur rumah tinggal di suatu kawasan.

\section{Analisis}

\subsection{Kondisi Geografis}

Kecamatan Lasem mempunyai luas wilayah dari pesisir Laut Jawa hingga ke selatan. Disebelah timur terdapat gunung Lasem. Wilayahnya seluas 4.504 ha. 505 ha diperuntukkan sebagai permukiman, 281 ha sebagai lahan tambak, 624 ha sebagai hutan milik Negara. Letaknya yang dilewati oleh jalur pantura, menjadikan kota ini sebagai tempat yang strategis dalam bidang perdagangan dan jasa. Kecamatan Lasem terdiri atas 20 desa yang terbagi ke dalam 84 Rukun Warga (RW) dan 219 Rukun Tetangga (RT), dengan ibukota kecamatan di desa Soditan. Adapun desa-desa tersebut adalah sebagai berikut: Babagan, Binangun, Bonang, Dasun, Dorokandang, Gedongmulyo, Gowak, Jolotundo, Kajar, Karangturi, Karasgede, Ngargomulyo, Ngemplak, Selopuro, Sendangsari, Sendangcoyo, Soditan, Sriombo, Sumbergirang, dan Tasiksono. Empat desa diantaranya berada di gunung Lasem yaitu desa Gowak, Kajar, Sangangcoyo dan Ngargomulyo sedangkan 5 desa di antaranya merupakan desa pesisir yang berbatasan langsung dengan laut Jawa. Lima desa tersebut meliputi Bonang, Dasun, Binangun, Gedongmulyo dan Tasiksono; dan 8 desa masuk dalam kawasan kota Lasem, yaitu Dorokandang, Karangturi, Soditan, Godongmulyo, Ngemplak, Babagan, Jolotundo dan Sumbergirang. Bukti eksistensi kebudayaan Tionghoa di Lasem adalah keberadaan ketiga kelenteng yang sudah berumur ratusan tahun. Ketiga kelenteng tersebut dapat dilihat pada tabel 1. Kelenteng $\mathrm{Cu}$ An Kiong adalah kelenteng tertua yang pertama didirikan di Lasem, menyusul yang tertua kedua Kelenteng Poo An Bio, dan yang ketiga Gie Yong Bio.

Tabel 1. Kelenteng di Lasem

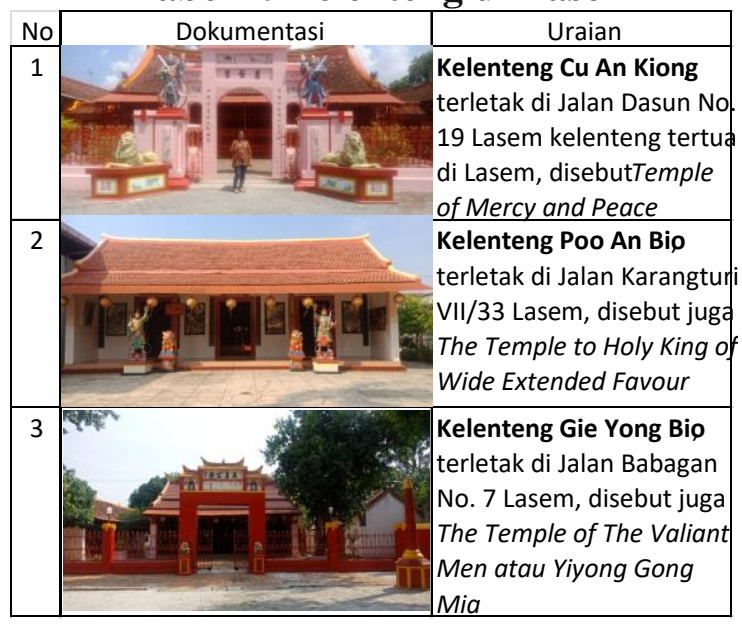

\section{2. Sejarah Kota Lasem}

Sejarah Kota Lasem yang tercatat dalam buku "Kawitane Wong Jowo Kanung" menceritakan Hang Sam Badra, penguasa kerajaan Pucangsulo di Kota Lasem tahun 380 M, memiliki keturunan Dewi Sima dan Dewi Siba. Tahun 1345 M, Lasem dibawah pimpiman Akuwu Lasem Mpu Metthabadra, keturunan Hang Sam Badra, berhasil ditaklukan oleh pasukan Majapahit di bawah pimpinan Patih Arya Gajah atas perintah Prabu Hayam Wuruk (Gunawan, dkk. 2008: 57). Sejak saat itu Kota Lasem berada di bawah kekuasaan kerajaan Majapahit dan kemudian dibentuk Kerajaan Lasem untuk diserahkan kepada kerabat Raja Hayam 
Wuruk yakni Dewi Indu (Suliyati, 2009:10). Dewi Indu merupakan ratu pertama Kerajaan Lasem dan bergelar Bhre Lasem tahun 1273 saka atau 1351 Masehi.Sumber-sumber sejarah lokal menyebutkan bahwa pada tahun 1351 Lasem diperintah oleh Dewi Indu, seorang adik sepupu raja Hayam Wuruk. Dewi Indu bersuamikan Pangeran Rajasa Wardhana yang memiliki kekuasaan yang terbentang dari daerah Pacitan sampai ke muara Bengawan Solo. Berdasarkan informasi tersebut dapat diperkirakan bahwa Lasem merupakan salah satu pusat kerajaan Majapahit. Pentingnya Lasem bagi Majapahit dapat dilihat dari kenyataan bahwa raja Hayam Wuruk pernah berkunjung ke Lasem pada tahun 1354. Dari kitab Negara Kertagama diketahui bahwa Majapahit memiliki beberapa kerajaan vasal di Jawa yang dipimpin oleh Paduka Bhattara atau Bhre antara lain: Daha, Wengker, Matahun, Lasem, Pajang, Peguhan, Singasari, Wirabhumi, Mataram, Kahuripan, dan Panawuhan. Bhre Lasem juga menjadi salah seorang anggota dewan penasihat raja Majapahit atau Bhattara Saptaprabhu yang beranggotakan tujuh orang. Sejak zaman kerajaan Majapahit, Lasem telah menjadi salah satu pusat pembuatan kapal. Penemuan situs kapal di Lasem barangkali juga merupakan indikasi bahwa Lasem merupakan pusat perkapalan kuno.

\section{3. Sejarah Masuknya Etnis Tionghoa di Kota Lasem}

Sejarah daratan Tiongkok datang ke Pulau Jawa pertama kali tahun $1416 \mathrm{M}$ melalui Lasem (Anonim, 2011). Tujuan utama etnis Tionghoa melakukan perjalanan ke wilayah-wilayah di luar Cina termasuk Indonesia adalah untuk melakukan perdagangan. Peristiwa ini terjadi pada pemerintahan Dinasti Ming yang berlangsung pada tahun 1368-1643 M. Selain melakukan perdagangan, Dinasti Ming berusaha memperluas wilayah protektoratnya ke wilayah Asia Tenggara termasuk Indonesia. Laksamana Ceng Ho mendapatkan Mandat untuk melakukan perjalanan ke Indonesia. Ceng Ho melakukan pelayaran sebanyak 7 kali ke Indonesia dan selama itu Ia berlayar 6 kali ke Pulau Jawa (Suliyati, 2009: 11). Etnis Tionghoa yang pertama kali mendarat di Lasem kemudian bermukim di desa Galangan tepatnya di tepi sungai Babagan (Rachman dkk., 2013: 25). Tepi sungai merupakan tempat ideal untuk mengembangkan peradaban, karena aliran sungai memicu aktivitas perdagangan dan transportasi masyarakat. Awal abad ke-16, sepeninggal Pangeran Wiranegara, Kerajaan Lasem berganti status menjadi

Kadipaten Lasem. Kadipaten Lasem dipimpin oleh Adipati Tejokusumo pada tahun 1628, masa kolonialisme VOC. Tahun 1750 ibukota Kadipaten Lasem dipindahkan ke Rembang, diikuti dengan pindahnya benteng VOC. Sejak 1751 Lasem berstatus sebagai kota kecamatan sampai dengan sekarang (Anonim, 2011).

\section{Arsitektur Rumah Lasem}

David G. Khol menulis dalam buku Chinese Architecture in The Straits Settlements and Western Malaya (1984), ciriciri dari arsitektur orang Tionghoa terutama di Asia Tenggara adalah sebagai berikut.

1) Adanya"courtyard;"

2) penekanan pada bentuk atap yang khas;

3) elemen-elemen struktural yang terbuka (yang kadang-kadang disertai dengan ornamen ragam hias); dan

4) penggunaan warna yang khas. Mengulik karakteristik arsitektur Rumah Tinggal Lasem, secara khusus dapat ditunjukkan dengan adanya:

1. Denah, secara garis besar bentuk rumah tinggal Cina di Lasem memiliki kesamaan ragam. Model tipikal ini ditemui hampir di semua lingkungan. Pola bangunan yang ada dibagi menjadi tiga yaitu: 1) rumah utama yang berada di tengah sebagai rumah induk, 2) rumah samping, dua bangunan yang terletak di kiri dan kanan bangunan utama berfungsi sebagai tempat tinggal bagi para anak cucu. Rumah 
Utama, merupakan pusat dari sebuah rumah tinggal yang dikelilingi oleh rumah-rumah yang lebih rendah.

2. Wuding atau Bentuk Atap

Bentuk atap arsitektur China paling mudah ditengarai. Diantara semua bentuk atap arsitektur Cina hanya ada beberapa yang paling banyak di pakai di Indonesia terutama di Lasem. Diantaranya jenis atap pelana dengan ujung yang melengkung keatas yang disebut sebagai model Ngang Shan. Menurut Pratiwo (2010:212), jenis ekstensi atap yang terdapat di rumah Lasem yaitu ekor burung wallet (pucuk jerami) dan mahkota (gulungan ombak). Bentuk atap pada gerbang rumah Lasem memiliki kesamaan dengan atap yang terdapat pada rumah. Hanya atap pada gerbang dimensinya lebih kecil dan bentuk lebih sederhana jika dibandingkan atap rumah utama.Sistem struktur yang dipakai pada rumah Lasem adalah berbentuk gable atau gunungan dan konstruksi kuda-kuda.

3. Gerbang, pada entrance rumah tinggal Lasem diawali dengan pintu gerbang yang terletak satu garis dengan pintu masuk bangunan serta altar. Sumbu ini memenuhi nilai simetri bangunan yang membagi rumah menjadi dua bagian yang sama dan menjadi ciri khas arsitektur rumah tinggal Cina. Secara umum bentuk gerbang yang ada di Lasem dibedakan dua jenis, yaitu 1) gerbang yang berbentuk gapura, 2) gerbang yang berbentuk rumah.

\section{Tabel 2. Bentuk Gerbang Rumah}

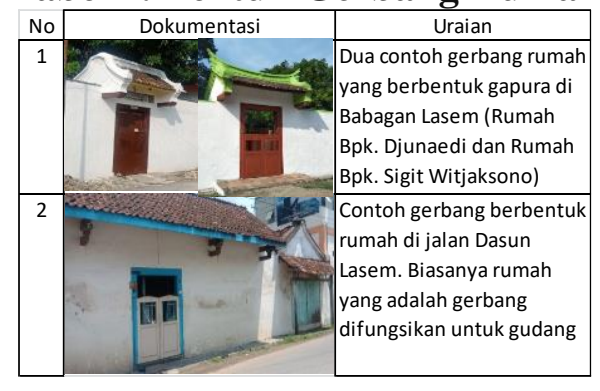

Bentuk gapura memiliki dinding pagar yang mengitari bangunan secara keseluruhan dan memiliki ketinggian hampir setinggi dinding rumah. Lantai pada gerbang biasanya memiliki peninggian lantai terutama pada bagian yang dipergunakan sebagai jalan masuk ke dalam rumah. Pintu yang digunakan biasanya memiliki model dua pintu dimana umumnya terpasang nama pemilik rumah.

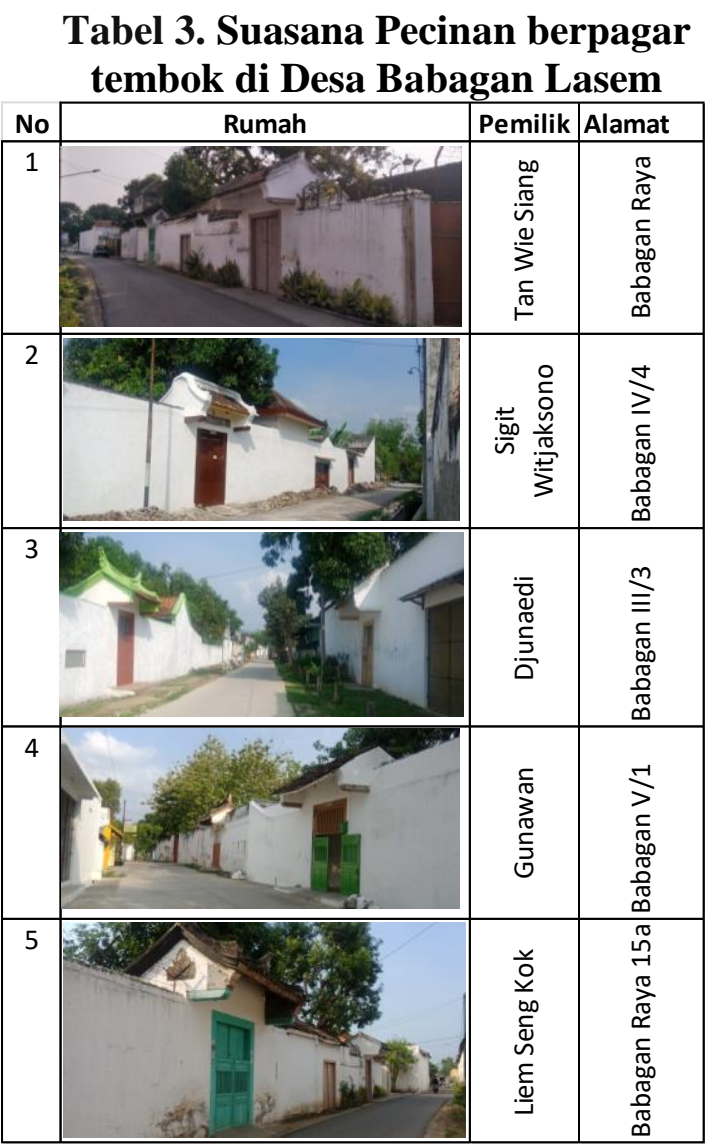

4. Tou-Kung

Keistimewaan yang menonjol dari arsitektur Cina terletak pada unsur Tou Kung yang berfungsi untuk menyangga atap kantilever. Bisa diletakkan pada kolom tengah, kolom sudut atau balok diantara dua kolom. Tou disebut juga balok tangan yaitu sebagai balok panjang yang menahan beban dari purlin (balok gording bulat panjang yang menahan kaso), Kung disebut juga lengan yaitu unsur kung yang berjejer berturutturut.

5. Courtyard atau Ruang Terbuka, merupakan ruang antar bangunan yang berbentuk persegi. Ruang terbuka ini 
biasanya juga difungsikan sebagai taman dengan berbagai tanaman di dalam rumah. Dalam kosmologi Cina, jagad raya berbentuk persegi dan terbagi menjadi empat kuadran, dengan Putra Langit (Kaisar Cina) berada tepat di tengahtengahnya. Titik tengah, sebagai singgasana Putra Langit, dikaitkan dengan tanah (Pratiwo, 2010). Hal ini disesuaikan dengan pandangan hidup masyarakat etnis Tionghoa yaitu dekat dengan tanah atau bumi (close to earth). Artinya jika manusia dekat dengan bumi atau tanah maka kesehatannya akan terjamin (Puspa, dkk., 2000: 26--27). Ruang terbuka pada bagian belakang rumah Lasem umumnya tidak terawat dan ditumbuhi rumput liar serta biasanya untuk membuang limbah batik. Pada beberapa rumah Lasem, halaman belakang terkadang lebih luas daripada rumah utama.

6. Altar, menurut Khaliesh (2014), Persamaan karakteristik Arsitektur tradisional Tionghoa di berbagai tempat menggambarkan tingkat eksistensi identitas Arsitektur Tionghoa masih tetap terjaga. Faktor yang paling berpengaruh terhadap tingkat eksistensi identitas Arsitektur tradisional Tionghoa adalah kepercayaan. Kepercayaan masyarakat Tionghoa pada ajaran leluhurnya juga-lah yang menjadi faktor utama eksistensi budaya masyarakat Tionghoa di berbagai tempat. Hal ini diwujudkan dalam ruang pemujaan leluhur di rumah tinggalnya.

7. Feng Shui

Masyarakat Cina di Lasem membangun tembok yang memisahkan pemukiman mereka dari masyarakat lain bukan karena alasan keamanan semata. Hal ini disebabkan warga Tionghoa Lasem membuat permukiman berdasarkan kosmologi yang diajarkan secara turun temurun. Tembok kokoh yang dibangun mengelilingi bangunan merupakan representasi kekuatan dan memiliki kosmologi tersendiri. Gerbang merupakan representasi dari Merak Merah. Pada bagian pintu (Merak Merah) terdapat tulisan kaligrafi Cina. Ada dua macam kaligrafi yang dipahat pada pintu, yaitu yang menonjol dan yang berupa pahatan ke dalam. Tulisan semacam ini disebut Cio, Lay, Hwat, Srikaya, yang katakatanya jika diterjemahkan ke dalam bahasa Melayu memiliki makna menggapai (meraih), supaya rejeki datang dan bertambah kaya. Rumah Samping, merupakan representasi dari Harimau Putih atau Singa di sisi kanan rumah utama dan Naga Biru di sisi kiri rumah utama (Nurhajarini dkk., 2015).

\section{Studi Kasus: Rumah Liem King Siok}

Rumah Liem dibangun pada tahun 1860-an. Pemiliknya adalah seorang Tionghoa bernama Liem King Siok yang merupakan saudagar cukup ternama sekaligus pimpinan masyarakat Tionghoa di Lasem.Rumah Liem terletak di Jalan Dasun, Desa Soditan, Kecamatan Lasem.

Rumah ini bisa dikatakan sebagai living monument yang menjadi saksi kejayaan Liem King Siok dan juga perkembangan Kota Lasem pada pertengahan abad ke-19 dan menjadi salah satu bangunan peninggalan masa Kolonial yang kondisinya tidak terawat.

Kompleks rumah Liem Kok Sing yang disebut juga Rumah Lawang Ombo memiliki lahan seluas 5.500 meter persegi dan dikelilingi tembok setinggi 1,5 meter. Pintu gerbangnya sejajar lurus dengan pintu rumah dan segaris dengan altar di ruang tengah rumah. Berikut ini adalah beberapa unsur arsitektur yang diterapkan pada rumah besar tempat tinggal Liem King Siok.

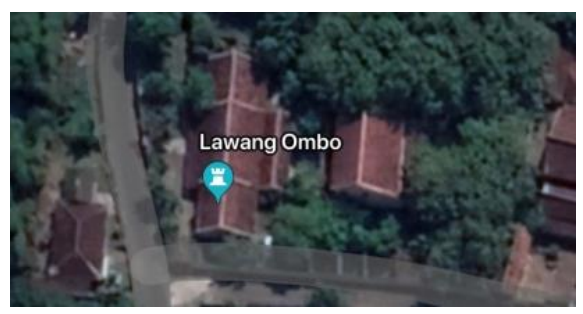




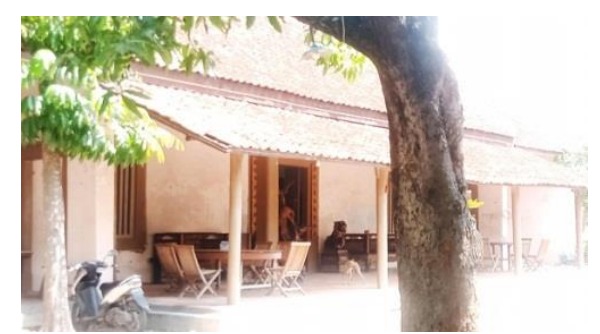

Gambar 1. Rumah Liem King Siok

\subsection{Unsur Arsitektur Cina}

Ciri-ciri karakteristik arsitektur Cina pada rumah Liem, ditunjukkan dengan adanya denah yang seperti banyak rumah Tionghoa awal di Indonesia, denahnya mencakup tiga bangunan parallel yaitu rumah pertama, rumah kedua (rumah utama) dan rumah ketiga dengan courtyard terbuka di antaranya. Sayangnya untuk bangunan ketiga bagian belakang dan bangunan samping sudah rusak. Bangunan pertama dan ketiga bertingkat tunggal sementara yang di tengah memiliki dua lantai dan ditinggikan di atas lahan yang sedikit lebih tinggi dengan dinding yang dibangun dari batu bata merah. Pada bagian utara terdapat rumah samping, tetapi kondisi sudah rusak dan pada bagian selatan ada makam pemilik rumah yang berbentuk tapal kuda. Sebagai tanggapan atas curah hujan, ada teras luas di bagian depan dan belakang bangunan, dengan yang satu bangunan depan memanjang sebagai atap gudang.

Bentuk atap merupakan bentuk atap arsitektur Cina yang paling banyak digunakan di Lasem pada khususnya dan Indonesia pada umumnya yaitu bentuk atap Ngang Shan. Sistem struktur yang dipakai pada rumah Liem adalah berbentuk gable atau gunungan dan konstruksi kuda-kuda. Sayangnya konstruksi kuda-kuda sudah mulai rusak dan lepas kayunya. Tou-Kung merupakan keistimewaan yang paling menonjol dari arsitektur Cina.Tou Kung di rumah ini berfungsi untuk menyangga tepi atap kantilever. Gerbang asli pada rumah ini merupakan bentuk gerbang gapura Cina.Sayangnya gerbang asli sudah rusak dan diganti dengan yang baru.

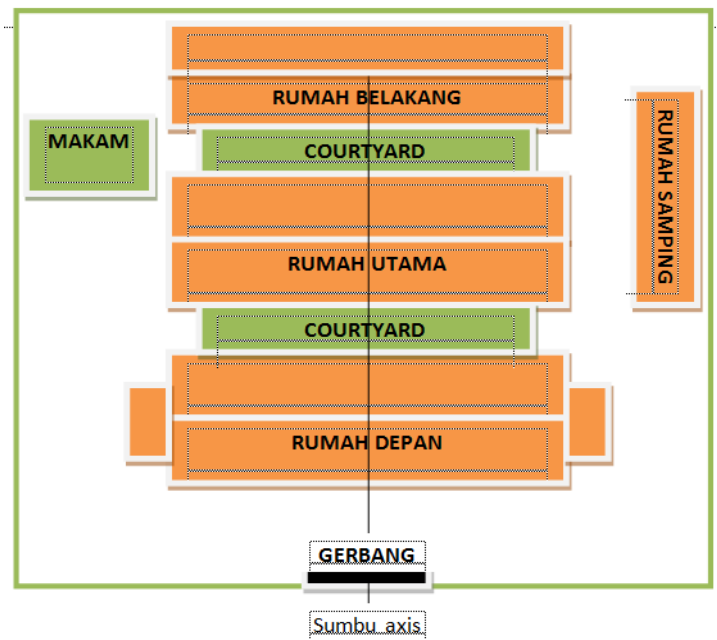

Gambar 2. Lay Out Plan

Rumah Liem King Siok

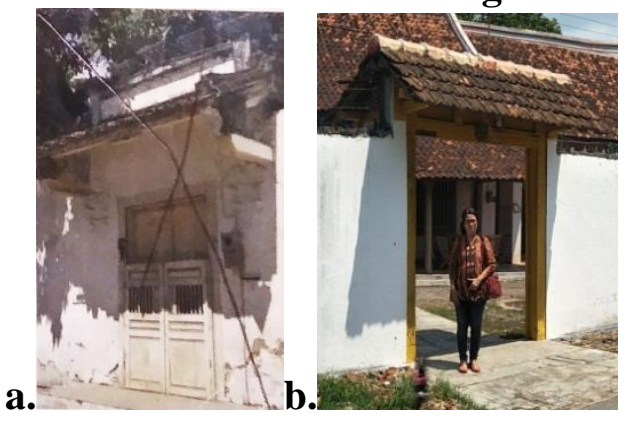

Gambar 3. a) Gerbang asli (Sumber: G. Knapp, 2010) 3. b) Gerbang perubahan (2018)

Keberadaan courtyard atau ruang terbuka di dalam rumah Liem Kok Sing menjadikan rumah terasa lebih sejuk, karena ketersediaan udara segar tercukupi. Selain sebagai sumber udara segar, pada courtyard ini juga terdapat sumber air atau sumur yang masih difungsikan hingga saat ini, yaitu di sayap kanan rumah atau di sebelah utara. Altar rumah Liem berada di ruang tengah dan menjadi titik orientasi utama rumah tinggal. Ornamen yang ada pada rumah ini berupa ukiran pada daun pintu. Ornamen lain hiasan khas berupa tulisan Cina yang terdapat pada sisi kanan dan kirin pintu masuk utama semakin menguatkan identitas kecinaan pemilik rumah. Selain itu terdapat patung singa di kanan kiri pintu masuk rumah. Fungsi dari kedua patung binatang ini adalah sebagai penjaga rumah untuk pengusir setan ataupun pengaruh buruk yang akan masuk ke dalam rumah 
Tabel 4. Detail Rumah Pertama

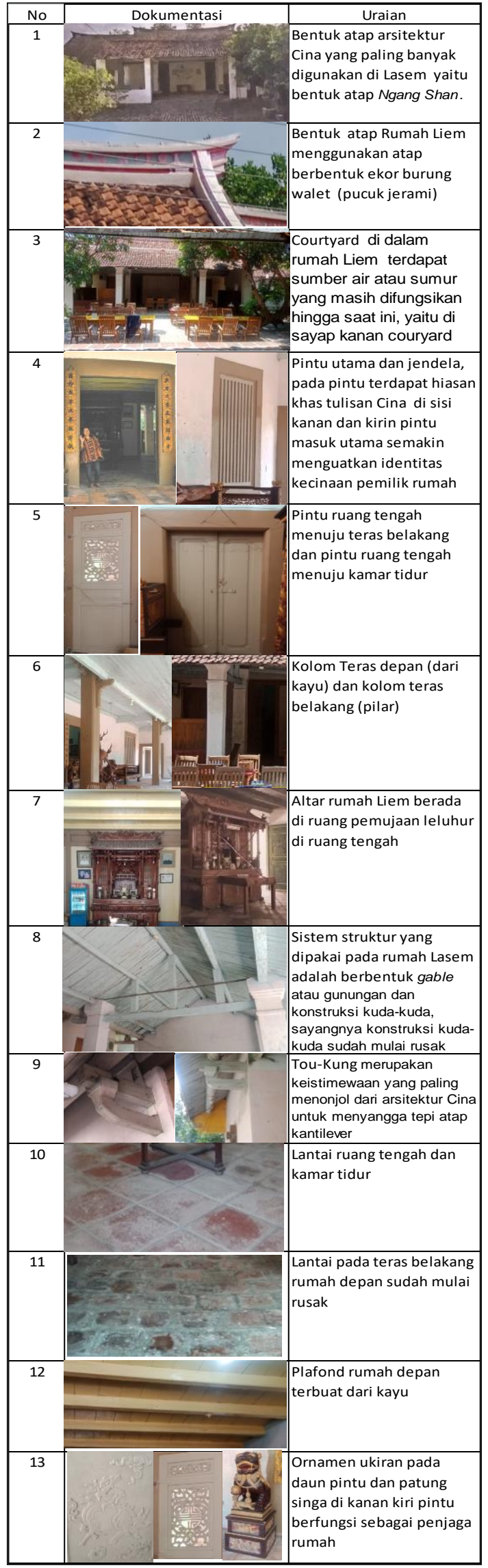

Tabel 5. Detail Rumah Kedua

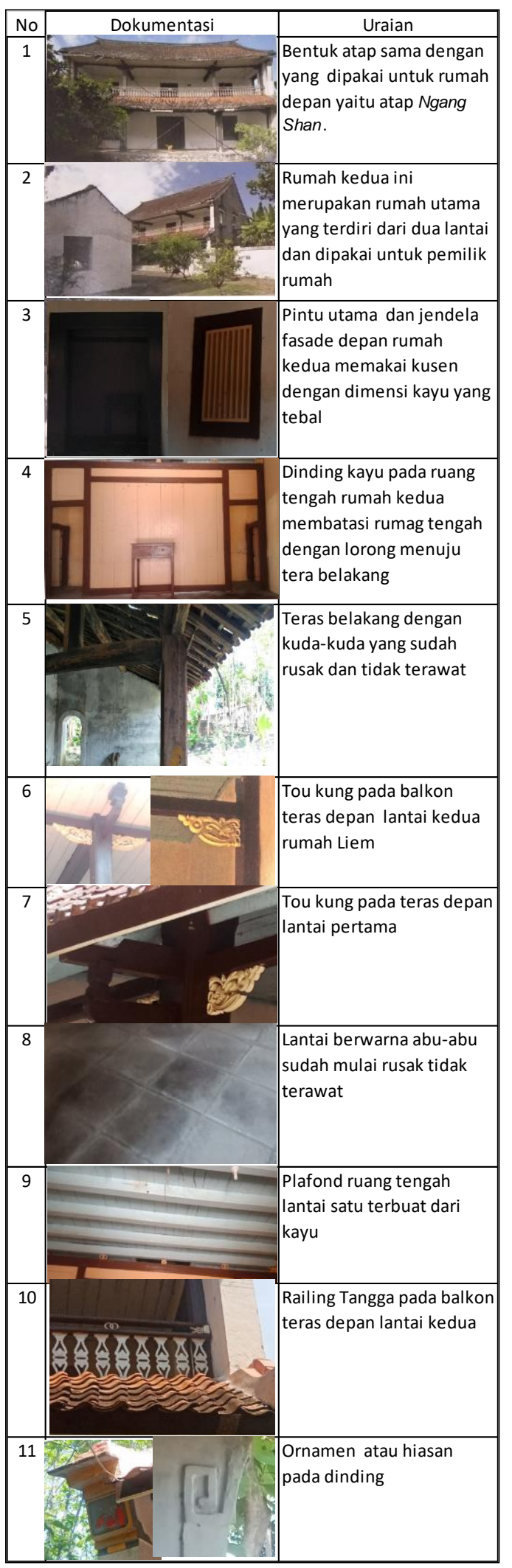




\section{2. Pengaruh Arsitektur Jawa}

Daerah Pantai Utara Jawa Tengah sejak lama telah berperan sebagai Bandar perdagangan internasional, sehingga terbentuk permukiman masyarakat Cina di daerah pesisir Utara Pulau Jawa. Selanjutnya terjadi akulturasi budaya Cina dengan setempat. Demikian pula dengan perkembangan arsitekturnya. Pada awalnya arsitektur rumah tinggal masyarakat pesisir Utara hanya didominasi dengan arsitektur tradisional Jawa, maka dengan terbentuknya permukiman Cina tersebut memberi warna pada arsitektur rumah tinggalnya (Darmawan, 2012:42). Arsitektur rumah Cina di Lasem adalah hasil arsitektur khas Cina Lasem yang merupakan perpaduan antara arsitektur Cina, Selatan (tempat asal sebagian besar orang Cina yang ada di Lasem), arsitektur Jawa (Pesisiran), dan pengaruh arsitektur Kolonial Belanda, yang mengalami perkembangan dari waktu ke waktu. Arsitektur di Lasem berkembang sesuai dengan perubahan zaman yang terjadi. Perkembangan arsitektur sebelum penjajahan Belanda berbeda dengan arsitektur pada waktu penjajahan dan berbeda pula dengan arsitektur modern yang sekarang (Handinoto, 2015:110).

Orang Cina di masa lalu mempunyai penafsiran yang tepat dalam berarsitektur, bahwa manusia tidak dapat dipisahkan dari makhluk sosialnya. Itulah sebabnya bangunan yang didirikan oleh orang Cina pada awalnya merupakan wujud dari pola kosmik dan merupakan simbolisme dari arah, musim, angina, dan masalah kosmologi lainya (Handinoto, 2015:112). Nilai kosmis dalam arsitektur Tionghoa adalah filosofi hubungan antara bangunan dan tanah, bangunan dan langit, dan hubungan antara keduanya. Baik etnis Jawa maupun etnis Cina memiliki keterkaitan genealogis yang terpaut ratusan generasi sehingga keduanya memiliki kemiripan unsur budaya. Contohnya dalam ritual seremonial yang membentuk realisasi konsep meminta ijin sambil menunjukkan rasa terima kasih selalu dilakukan di rumah tengah (omah tengah) yang dibiarkan kosong. Dalam rumah etnik Jawa, bagian yang digunakan untuk menerima tamu memiliki atap yang membentuk satu kesatuan dengan bangunan utama, yaitu di teras depan atau teras disebut jogan/jogo satru. Meskipun atap ini terkait dengan salah satu yang meliputi bangunan utama, ruang ini dibiarkan terbuka, tanpa dinding atau pintu (Fauzy dkk., 2012).

Pengaruh unsur arsitektur Jawa yang muncul pada bangunan rumah Liem King Siok antara lain terdapat pada: rumah tengah (omah tengah) tempat untuk melakukan ritual seremonial dan teras (pendhopo) tempat untuk menerima tamu.

\section{3. Pengaruh Arsitektur Kolonial}

Dalam periodisasi perkembangan arsitektur Kolonial Belanda di Indonesia, Hellen Jessup (dalam Handinoto, 1996: 129130) membaginya menjadi empat tahap dari abad ke-16 sampai dengan tahun 1940, yaitu: a) abad ke-16-tahun 1800-an; b) tahun 1800an- 1902; c) tahun 1902-tahun 1920-an; d) tahun 1920 -1940-an. Dilihat dari segi waktu, maka bangunan rumah Liem King Siok dipengaruhi oleh gaya arsitektur Kolonial periode kedua karena bangunan ini dibangun abad ke-19, tepatnya tahun 1860. Pada masa itu bangunan Kolonial umumnya mempunyai arsitektur dengan gaya yang disebut sebagai Indische Empire atau Dutch Indies atau Dutch Colonial Villa. Gaya empire ini berasal dari vila dinasti Lodewijk abad 18 di Perancis (Handinoto, 1990: 8). Di Indonesia bangunan-bangunan tersebut disesuaikan dengan lingkungan lokal, iklim, dan material yang tersedia pada masa itu, sehingga menghasilkan suatu arsitektur yang dikenal dengan arsitektur Indis. Bangunan-bangunan ini umumnya berkesan grandeur (megah) dengan gaya Neoklasik. Oleh karena itu, Pemerintah Kolonial Belanda menjadikan arsitektur Indis ini sebagai standar dalam pembangunan gedung-gedung, baik milik pemerintah maupun swasta. Bentuk tersebut ditiru oleh mereka yang berkecukupan, terutama para pedagang dari etnis tertentu, dengan harapan agar memperoleh kesan pada 
status sosial yang sama dengan para penguasa dan bangsawan. Penyesuaian bentuk bangunan Indis terhadap kondisi iklim tropis basah digambarkan dengan ciri-ciri pokok bentuk plafon tinggi, overstek yang cukup lebar, adanya beranda-beranda yang cukup dalam, baik di depan atau di belakang rumah. Plafon yang tinggi akan mempunyai volume ruang yang lebih besar, sehingga kemungkinan terjadi panas dalam ruangan akibat radiasi dapat diperkecil. Overstek yang cukup lebar dapat dipakai untuk menahan tampias air hujan, dan juga untuk pembayangan terhadap tembok yang terkena sinar matahari langsung (Handinoto,1996: 30).

Pengaruh unsur arsitektur Kolonial yang muncul pada bangunan rumah Liem King Siok antara lain terdapat pada: tiang dan plafon. Salah satu unsur yang menonjol dalam arsitektur Indis adalah tiang, karena bangunan akan nampak megah jika menggunakan pilar (tiang) yang berpengaruh pada plafon yang tinggi. Unsur tiang dan plafon seperti ini ditemui pada bangunan rumah Liem King Siok. Dalam arsitektur rumah tinggal Cina yang tradisional biasanya cenderung menggunakan pilar kayu dengan hiasan baik pada kaki(umpak) maupun pada kepala pilar (Kohl, 1994: 43).

\section{Simpulan}

Akulturasi budaya dalam arsitektur rumah tinggal Cina di Lasem pada abad ke19 adalah hasil arsitektur khas Cina Lasem yang merupakan perpaduan antara arsitektur Cina Selatan (tempat asal sebagian besar orang Cina yang ada di Lasem), arsitektur Jawa (Pesisiran), dan pengaruh arsitektur Kolonial Belanda, yang mengalami perkembangan dari waktu ke waktu. Rumah tinggal Liem King Siok merupakan salah satu bangunan peninggalan sejarah masa kolonial di Kota Lasem. Arsitektur rumah ini memiliki keunikan, karena menerapkan beberapa gaya arsitektur sekaligus, yaitu Cina, Jawa, dan Kolonial(Indis). Semua gaya arsitektur tersebut berpadu dalam bentuk akulturasi arsitektural dengan menyesuaikan kondisi alam setempat sehingga tercipta suatu bangunan indah dan megah yang sayangnya kurang mendapatkan perawatan. Penggunaan arsitektur Cina dalam bangunan ini adalah untuk mencerminkan identitas dirinya sebagai orang Tionghoa. Unsur budaya lokal, yaitu Jawa, lebih mencerminkan upaya Liem King Siok untuk menjadi bagian dari budaya setempat di mana dia bermukim sehingga tidak dianggap sebagai orang asing. Sedangkan unsur Kolonial digunakan karena memberikan kesan megah, kokoh, serta merefleksikan tingkat status sosial dan ekonomi si pemilik rumah.

Arsitektur rumah tinggal Lasem merupakan pusaka kota yang perlu dipertahankan sebagai identitas khas Lasem karena merupakan hasil akulturasi budaya yang jarang ditemui di luar Kota Lasem. Selain sebagai bukti kesuksesan seorang Cina di perantauan, rumah besar Liem King Siok juga merupakan aset kota Lasem (sebagai kekayaan budaya lokal). Oleh karena itu bangunan yang sekarang menjadi monumen hidup (living monument) ini harus dijaga dan dipelihara supaya tidak rusak dan tidak hilang bentuk aslinya.

\section{Daftar Pustaka}

Afifah, dkk. 2007. Eklektisisme dan Arsitektur Eklektik. Yogyakarta: Gadjah Mada University Press.

Anonim. 2011. Sejarah Kota Lasem. (http://titdtrimurtilasem.blogspot.com/ 2 11/07/sejarah-kota-lasem.html diakses pada 22 November 2018 pukul 11:25 WIB).

Darmawan, D. 2012. The Influence of Yin Yang School of Thought towards the Architecture of Chinese's Old Residential Buildings at Lasem. Jurnal Tesa Arsitektur, 10(1), 42-51.

Fauzy, Bachtiar, 2012, Konsep Kearifan Lokal Dalam Arsitektur Rumah Tinggal Masyarakat Kota Pesisir Utara Jawa Studi Kasus: Arsitektur Rumah Tinggal di Kampung Sumber Girang 
Lasem Bandung: Laporan Penelitian Arsitektur LPPM Unpar.

Gunawan, Y. F., Rachim \& C. Fabiano. 2008. Arsitektur Vernakular Seri 2. Pertemuan Arsitekiur Pantai Utara Jawa: Cirebon, Tegal, Pekalongan, Semarang, Lasem, Tuban. Bandung: Cipta Sastra Saluran.

Handinoto. 2015. "Lasem: Kota Tua Bernuansa Cina di Jawa Tengah." Semarang: Jurusan Arsitektur Unika Sugijapranata.

Handinoto dan Hartono. 2005. "Lasem Kota Kuno di Pantai Utara Jawa yang Bernuansa China" dalam Prosiding Seminar Nasional Pemahaman Sejarah Arsitektur Indonesia X, Arsitektur Pecinan Di Indonesia. Semarang: Jurusan Arsitektur Unika Sugijapranata.

Handinoto. 1990. "Sekilas Tentang Arsitektur Cina Pada Abad ke-19 di Pasuruan". dalam Dimensi Arsitektur Vol.15/1990. Surabaya: Universitas Kristen Petra.

Khol, David G. 1984. Chinese Architecture in The Straits Settlements and Western Malaya: Temples Kongsis and Houses. Kuala Lumpur: Heineman Asia.

Koentjaraningrat. 1977. Antropologi Sosial, Beberapa Pokok. Jakarta: PT Dian Rakyat.

Nurhajarini, dkk. 2015. Akulturasi Lintas Jaman di Lasem: Perspektif Sejarah dan Budaya. Yogyakarta: Balai Pelestarian Nilai Budaya (BPNB).

Rachman, F.N. et. All. 2013. Lasem, Kota Sejarah yang Terpinggirkan Zaman. Bandung: Fokmas Lasem \& Rembang Heritage Society.

Soekiman, Djoko. 2000. Kebudayaan Indis. Yogyakarta: Bentang.

Suliyati, T. 2009. "Melacak Warisan Budaya Cina di Lasem." Seminar Nasional, dengan tema "Menyusur Sungai Meretas Sejarah Cina di Lasem."

Pratiwo. 2010. Arsitektur Tradisional Tionghoa dan Perkembangan Kota. Yogyakarta: Ombak.
Purwanto \& Yulita. 2017. Acculturation in the Architecture of Lasem City. Asian Journal of Engineering and Technology (ISSN: 2321 - 2462) Volume 05 - Issue 02, April 2017.

Puspa, Dewi, dkk. 2000. Kelenteng Kuno di DKI Jakarta dan Jawa Barat. Jakarta: Depdiknas

Sopandi, Setiadi. 2013. Sejarah Arsitektur, Sebuah Pengantar. Jakarta: Anggota IKAPI. 